\title{
MICROLEAKAGE EVALUATION OF THREE GLASS IONOMER CEMENTS USED IN CHILDREN: IN-VITRO STUDY
}

\author{
Dalia A.M. Talaat*
}

\begin{abstract}
Purpose: To assess in-vitro the marginal adaptation of three types of glass ionomer cements in in class $\mathrm{V}$ primary molars.

Materials and Methods: The sample included thirty sound exfoliated or extracted primary molars for orthodontic purpose. The teeth were divided into 3 equal groups of 10 teeth each according to the type of the restorative material used. Group I were restored with ceramic reinforced glass ionomer, group II were restored with resin modified glass ionomer and group III were restored with conventional glass ionomer. After thermocycling, the teeth were immersed in $2 \%$ methylene blue solution for 24 hours, then they were sectioned buccolingually. The extent of dye penetration was detected using a stereomicroscope.

Results: Ceramic reinforced glass ionomer showed the lowest mean microleakage value at both occlusal and gingival margins as compared to the other two groups with statistically significant difference. No statistically significant difference in the mean microleakage was recorded between the resin modified and conventional glass ionomers
\end{abstract}

Conclusion: Ceramic reinforced glass ionomer revealed the highest sealing ability in class $\mathrm{V}$ primary molars when compared to the resin modified and conventional glass ionomer cements.

KEYWORDS: Microleakage, Glass ionomer cements, Class V, Primary molars.

\section{INTRODUCTION}

Dental caries is the disease most frequently transmitted in children ${ }^{(1)}$. Modern restorative care of decayed lesions is based on the minimal intervention approach, early interception and prevention ${ }^{(2)}$. Glass ionomer cement "GIC" was introduced to the profession fifty years ago and has been used in primary teeth since their introduction into the market. It possesses certain unique properties including release of anticariogenic fluoride into neighboring tooth structures, chemical bonding to enamel and dentine, and a low coefficient of thermal expansion comparable to the tooth structure ${ }^{(3)}$. Moreover, they

* Associate Professor of Pediatric Dentistry, Pediatric Dentistry and Dental Public Health Department, Faculty of Dentistry, Alexandria University, Egypt. 
are beneficial when treating young children as they are moisture tolerant and require short time to fill the cavity ${ }^{(4)}$. However, they are prone to fracture and show poor wear resistance ${ }^{(5)}$. Because of their low tensile strength, fracture toughness and brittleness, these deficiencies have limited their use and made them unsuitable for high-stress areas ${ }^{(6)}$. In order to enhance their mechanical properties, a number of modifiers have been applied to traditional GICs. The addition of polymerizable hydrophilic resin to conventional glass ionomer cements "CGICs" led to the production of resin-modified formulations that formed a dual reaction: the acid-base reaction and the process of free-radical polymerization ${ }^{(7)}$. These resin modified glass ionomer cements "RMGICs" show better mechanical properties than CGICs. Though there are individual differences from one brand to another, still their polymerization shrinkage and low wear resistance constitute major drawbacks ${ }^{(8,9)}$.

Advanced Healthcare, the UK's leading manufacturer of GIC introduced a ceramic-reinforced glass ionomer "CRGI" "Amalgomer CR" that offers dental professionals the established advantages of glass ionomers "GIs" combined with high compressive strength ${ }^{(10)}$. They are the first glass ionomer filling materials to achieve an excess of $300 \mathrm{MPa}$ at 24 hours after placement. Its compressive strength continues to increase, unlike amalgam, so that at one month after placement, they achieve $423 \mathrm{MPa}$ that is considered to be higher than most of composites used for posterior restorations. ${ }^{(11)}$

The manufacturer of Amalgomer CR claims that its material poses excellent wear characteristics, superior radiopacity, built to match amalgam strength and longevity, sustained high fluoride release levels, strong biocompatibility, and natural adhesion to the framework of the tooth ${ }^{(11)}$. Ayad et al, (12) found that CRGI exhibited notably higher compressive strength and tensile strength than amalgam. Also, Deepa and Shobha, ${ }^{(13)}$ concluded that overall success of Amalgomer CR is higher than RMGI. They referred this success to the ceramic reinforcement of glass ionomer which may be responsible for its high strength. Therefore, it becomes more resistant to wear and fracture than RMGI.

A restorative material should provide a longterm hermetic seal against bacterial penetration. This is especially important as microleakage is a main reason of restoration deterioration and may lead to secondary caries and pulpal irritation ${ }^{(14)}$. Few studies have examined the marginal microleakage of Amalgomer CR in class $\mathrm{V}$ primary molars. Therefore, this study aimed to assess and compare in-vitro marginal adaptation of CRGI "Amalgomer CR", RMGI and CGI in class V primary molars. The null hypothesis tested was that there is no difference between the CRGI, RMGI and CGI regarding their sealing ability in Class $\mathrm{V}$ primary molars restorations.

\section{MATERIALS AND METHODS}

This comparative in-vitro study was conducted after receiving approval from the Research Ethics Committee. Sample size was estimated based on assuming 5\% alpha error and $80 \%$ study power. The mean \pm SD of microleakge score was $1.3(0.6)$ for conventional GIC ${ }^{(15)}, 2.30$ (0.6) for resin modified glass ionomer and 1.8 (0.7) for Zirconia reinforced GIC that was assumed to have similar effect to ceramic reinforced GIC ${ }^{(16)}$. Using F test, sample size was calculated to be 10 teeth per group with total sample of 30 teeth. Sample size was estimated by Gpower 3.0.10.

\section{Study sample}

Thirty exfoliated human caries-free primary molars and extracted for orthodontic purposes or at shedding period were collected from out-patients attending the Pediatric Dentistry Clinic, Faculty of Dentistry, Alexandria University. All teeth were washed and preserved in purified water with $1 \%$ 
chloramines added to it at room temperature to prevent their dehydration before the restorative and testing procedure ${ }^{(17)}$.

\section{Materials}

The materials used in this study were ceramic reinforced glass ionomer (CRGI) "Amalgomer CR" (Advanced Health Care, Tonbridge, Kent, TN118JU, UK). It is composed of:

Powder: Fluoro-aluminosilicate glass, shade pigments, polyacrylic acid powder, tartaric acid powder and ceramic reinforcing powder

Liquid: Polyacrylic acid, disttilled water, resin modified glass ionomer (RMGI) "Fujii II LC" (GC America Inc, Chicago,USA). It is available in a disposable preloaded capsules and composed of:

Powder: Fluoro-aluminosilicate glass glass, shade pigments and

Liquid: Polyacrylic acid, 2 Hydroxyethyl methacrylate (HEMA), proprietary ingredient, Triethylene glycol methacrylate, 2,2,4, trimethyl hexamethylene dicarbonate (TMHMD), conventional glass ionomer (CGI) "Ketac Fil plus Aplicap" (3M ESPE, Seefeld, Germany). It is available in a disposable preloaded capsules and composed of:

Powder: Fluoro-aluminosilicate glass, shade pigments and

Liquid: Polyacrylic acid (acid inform of copolymer with itaconic, maleic, or tricarboxylic acid), tartaric acid and water.

\section{Cavity preparation}

Teeth included in the study were hand scaled, cleaned using pumice with low-speed handpiece then washed with water and stored in normal saline till use. Classs V cavities were prepared with a standard \# 330 carbide bur, on a high-speed water cooled handpiece. The bur was replaced every four preparations. The cavity outline followed the traditional resin restoration cavity preparation guidelines ${ }^{(18)}$. A millimeter ruler and a K-file were used for standardization purposes.

\section{Grouping}

Based on a simple random design using an ideal bowl technique, the 30 prepared primary molars were randomly divided according to the type of material used to restore the teeth into 3 equal groups "I, II and III". Group I were restored with CRGI "Amalgomer CR" group II were restored with RMGI "Fuji II LC" and group III were restored with CGI "Ketac Fil Plus Aplicap"

\section{Teeth restoration}

For all prepared cavities, they were rinsed with air/water spray then they were dried with oil free compressed air. Cavity conditioner was applied and left undisturbed for 10 seconds to remove smear layer and facilitate the chemical bond between glass ionomer and the dental hard tissues ${ }^{(19)}$. Then the cavity was washed with water for 10 seconds and gently air-dried for 5 seconds. For group I: Amalgomer CR was hand mixed: 1 powder scoop and 1 liquid drop "1:1" until achieving a homogenous consistency; then it was applied into the cavity. For group II: Fuji II LC capsule was mixed automatically for 10 seconds; applied incrementally less than $2 \mathrm{~mm}$ and each layer was light cured for 40 seconds. For group III: Ketac Fil Plus Aplicap capsule was automatically mixed for 10 seconds; then it was applied into the cavity. All steps were done according to manufacturers' recommendations. Restorations were finished and polished using a set of 4 "Sof-Lex" abrasive discs "coarse, medium, fine and superfine" "3M Dental Products, st. Paul, MN55144, USA”. After finishing, all exposed surfaces were coated with varnish and light cured for 10 seconds ${ }^{(20)}$.

\section{Microleakage evaluation}

Thermocycling was achieved with a thermal cycling machine that alters the temperature between thermostatically controlled water baths at $5^{\circ} \mathrm{C}$ and $55^{\circ} \mathrm{C}$ with a dwell time of 30 seconds in each bath, for about 1000 cycle $^{(21)}$. This aimed to simulate 
the temperature changes that take place in the oral cavity ${ }^{(22)}$. After thermocycling, the apical and furcation area of each tooth was sealed with chemical cure acrylic resin and sticky wax (DENTSPLY International Inc. Milford, DE $19963-$ 0359 USA). The whole surface of each tooth "with exception of the restorations and $1 \mathrm{~mm}$ around" was covered with a double layer of nail varnish to ensure proper isolation of teeth surfaces against dye penetration ${ }^{(23)}$. For 24 hours, in small dark closed bottles, specimens were soaked in $2 \%$ methylene blue solution away from sunlight ${ }^{(24)}$. After dye exposure, the teeth were cleaned and rinsed thoroughly with tap water for 5 minutes. Samples were longitudinally cut in a buccolingual direction through the middle of the restoration using a watercooled low-speed diamond saw. This resulted in 2 equal sections, both of which were analyzed for microleakage. Using a stereomicroscope (Olympus SZ1145, Olympus Optical Co., LTD. Tokyo, Japan) at 20x magnification, the cut surfaces of sectioned teeth were inspected and viewed. In accordance with the scoring system defined by Silveira de Araijo ${ }^{(25)}$ the degree of dye penetration was evaluated twice, one week apart, by the researcher at the occlusal and gingival margins of the restoration. The criteria used to score dye penetration were: Score $0=$ No evidence of dye penetration, score $1=$ Dye penetration along the occlusal/gingival wall to less than half of the cavity depth, score $2=$ Dye penetration along the occlusal/gingival wall to more than half of the cavity depth, but not extending on to the axial wall, score $3=$ Dye penetration along the occlusal/gingival wall to the full cavity depth and extending on to the axial wall (Fig 1). Both sections were graded and the section with the largest degree of occlusal and gingival microleakage was reported as the restoration score. The intra examiner reliability to determine the degree of dye penetration was assessed using Kappa test showed substantial agreement $\left(\mathrm{K}_{\mathrm{A}}=0.76\right)$

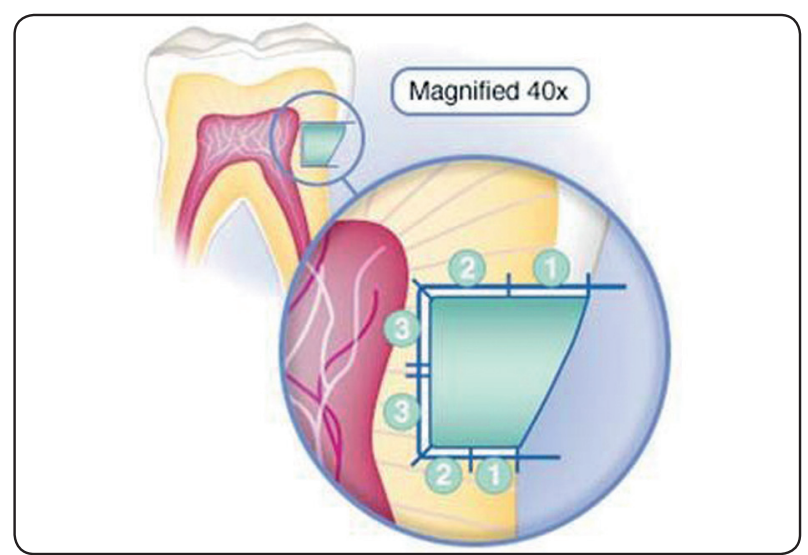

Fig. (1) Diagram showing scores of dye leakage (26).

\section{Statistical analysis}

Data were analyzed using SPSS version 25 (IBM Corp,Armonk:NY). Kruskal-Wallis test was applied to compare the microleakage scores between groups and followed by Dunn's post hoc test. Wilcoxon signed-rank was used to determine differences at occlusal and gingival margins. Significance level was set $\mathrm{P}$ value of 0.05 .

\section{RESULTS}

Within group comparison, findings revealed no statistically significant difference in the mean microleakage scores between the occlusal and gingival margins in group $\mathrm{I}(\mathrm{P}=0.317)$ (Table 1$)$. Ninety percent of teeth restored with CRGI were of score 0 at occlusal margin and $80 \%$ of teeth showed score 0 at gingival margin (Figs 2 and 3). However, there was a statistically significant difference between mean microleakage scores at occlusal and gingival margins in group II and III ( $\mathrm{P}=0.038,0.046$ respectively) where the gingival margins recorded higher mean microleakage values in both groups (Table 1). Microscopic examination revealed that $10 \%$ of teeth restored with RMGI were of score 0 at the occlusal and gingival margins, while none of the teeth restored with CGI showed score 0 at the occlusal or gingival margins (Figs 2 and 3 ). 
By comparing the mean microleakage scores of the three study groups at the occlusal margin, results showed a statistically significant difference between group I and group II and between group I and group III $(\mathrm{P}=0.010, \mathrm{P}<0.0001$ respectively $)$ where teeth restored with CRGI recorded the lowest mean microleakage scores occlusally. No statistically significant difference was recorded between group II and group III ( $\mathrm{P}=0.609)$ (Table 1).

Similarly, at the gingival margin there was a statistically significant difference between group

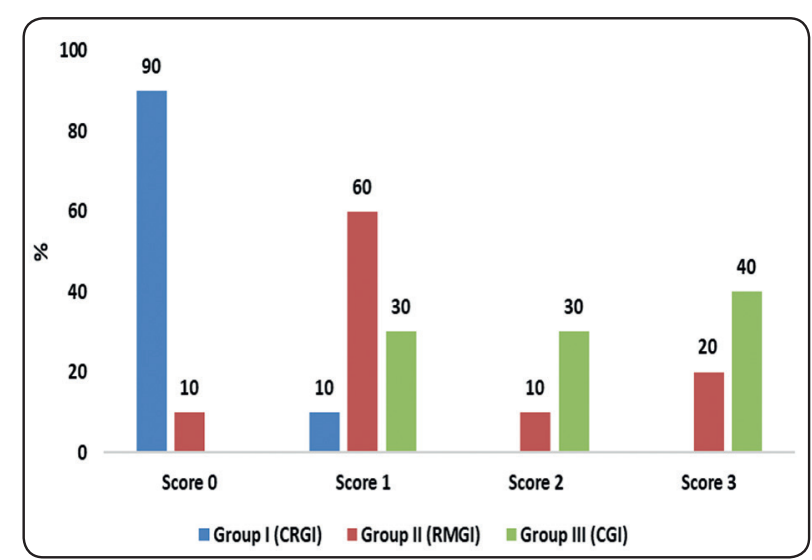

Fig. (2) Distribution of microleakage scores among the three study groups at occlusal margin.
I and group II $(\mathrm{P}=0.007)$ and between group I and group III $(\mathrm{P}<0.0001)$ in favor of group I, while there was no statistically significant difference between group II and group III ( $\mathrm{P}=0.494)$ (Table 1).

Results of the overall microleakage values of the three study groups showed lowest score for group I as compared to both group II and group III with statistically significant difference $(\mathrm{P}=0.012$, $\mathrm{P}<0.0001$ respectively). However, there was no statistically significant difference between group II and group III ( $\mathrm{P}=0.418)$ (Table 2).

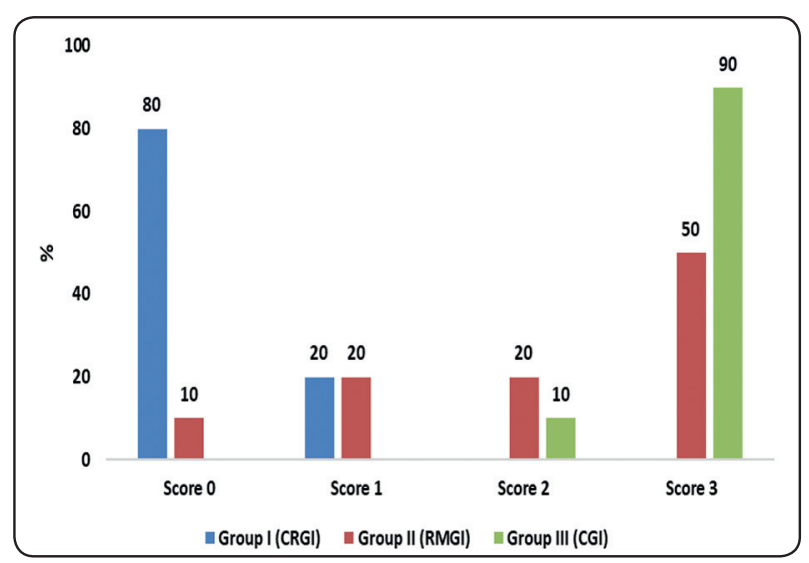

Fig. (3) Distribution of microleakage scores among the three study groups at gingival margin.

TABLE (1) Comparison of microleakage values between the three groups at the occlusal and gingival margin.

\begin{tabular}{|c|c|c|c|c|}
\hline & $\begin{array}{c}\text { Group I (CRGI) } \\
(\mathrm{n}=10)\end{array}$ & $\begin{array}{c}\text { Group II (RMGI) } \\
(\mathbf{n = 1 0})\end{array}$ & $\begin{array}{c}\text { Group III (CGI) } \\
(\mathbf{n = 1 0})\end{array}$ & \multirow[t]{2}{*}{$P$ value } \\
\hline & \multicolumn{3}{|c|}{ Mean (SD) } & \\
\hline Occlusal & $0.10(0.32)$ & $1.40(0.97)$ & $2.10(0.88)$ & $\begin{array}{l}\mathrm{P}_{1=} 0.010^{*}, \\
\mathrm{P}_{2}<0.0001^{*}, \\
\mathrm{P}_{3}=0.609\end{array}$ \\
\hline Gingival & $0.20(0.42)$ & $2.10(1.10)$ & $2.90(0.31)$ & $\begin{array}{l}\mathrm{P}_{1=} 0.007^{*}, \\
\mathrm{P}_{2}<0.0001^{*}, \\
\mathrm{P}_{3}=0.494\end{array}$ \\
\hline$P$ value & 0.317 & $0.038^{*}$ & $0.046^{*}$ & \\
\hline
\end{tabular}

*Statistically significant difference at $P$ value $\leq 0.05$

$\mathbf{P}_{1:}$ Differences between group I and II, $\mathbf{P}_{2:}$ Differences between group I and III, $\mathbf{P}_{3:}$ Differences between group II and III. 
TABLE (2) Overall microleakage values for the three groups.

\begin{tabular}{|c|c|c|c|c|}
\hline & $\begin{array}{c}\text { Group I (CRGI) } \\
(\mathbf{n = 1 0})\end{array}$ & $\begin{array}{c}\text { Group II (RMGI) } \\
(\mathbf{n = 1 0})\end{array}$ & $\begin{array}{c}\text { Group III (CGI) } \\
(\mathbf{n = 1 0})\end{array}$ & P value \\
\cline { 2 - 5 } & \multicolumn{3}{|c|}{ Mean (SD) } & $\begin{array}{c}\mathrm{P}_{1=} 0.012^{*}, \\
\mathrm{P}_{2}<0.0001^{*}, \\
\mathrm{P}_{3}=0.418\end{array}$ \\
\hline $\begin{array}{c}\text { Microleakge } \\
\text { values }\end{array}$ & $0.15(0.34)$ & $1.75(0.95)$ & $2.50(0.41)$ & \\
\hline
\end{tabular}

*Statistically significant difference at $P$ value $\leq 0.05$

$\mathbf{P}_{1:}$ Differences between group I and II, $\mathbf{P}_{2:}$ Differences between group I and III, $\mathbf{P}_{3:}$ Differences between group II and III.

\section{DISCUSSION}

The evolution of the dental materials is of great concern in the dental field. Amalgomer technology is an innovation in restorative dentistry. For the first time the strength of a classic amalgam has been combined with the aesthetic and many other benefits of GIs ${ }^{(27)}$. This study aimed to evaluate the microleakage of the CRGI in class V primary molars and compare it to that of RMGI and CGI.

Results of the present study did not record a significant difference between the mean microleakage scores at the occlusal and gingival margins in CRGI group. This finding agrees with El Negoly et al ${ }^{(28)}$. Regarding the RMGI group there was no significant difference in the mean microleakage scores between the occlusal and gingival margins, however, the latter recorded higher scores. Within the body of RMGI, adjacent to dentin, there is a non-particulate layer of solid material called the "absorption layer" grows over time and has been shown to be fundamentally weak. However, adjacent to the enamel this layer does not exist ${ }^{(29)}$. This may explain why there was more microleakage at gingival margin for RMGI. Moreover, when the RMGI is added to the irregular etched surface, the material monomers polymerize and the material becomes interlocked with the surface of the enamel forming the resin microtags. However, in dentin, because of the capillary pressure and dentinal fluid oozing out of the tubules, the resin is unable to penetrate far ${ }^{(20)}$. This could be a possible reason for RMGI showing more leakage in dentin. Same findings were reported by Maish et al (20) who demonstrated that at cervical margins, RMGI exhibited greater microleakage than occlusal margins.

As regard to the CGI Group, the mean microleakage value at the gingival margin was higher than that at the occlusal margin however, this difference was not notable. This agreed with Xie et $\mathrm{al}^{(30)}$ who found innotable difference between occlusal and gingival margin in CGICs. On the other hand, notable differences between occlusal and gingival CGIC scores were shown by Gupta et al ${ }^{(31)}$.

In the present study all the three materials recorded higher microleakage score at gingival margin than the occlusal margin. Therefore, no material was able to entirely stop microleakage at the gingival margin. This could be due to a drop in the number and thickness of cervical enamel rods and poor adherence of the material to the cervical margin. ${ }^{(32)}$ This finding agrees with the results of Puckette et al ${ }^{(33)}$ and Gupta et al ${ }^{(31)}$ who suggested that the interface for cervical enamel dentin / restoration is more susceptible to microleakage than other tooth / restoration interface locations.

Results of the present study partially reject the null hypothesis as by comparing the three study groups, CRGI showed the best sealing ability while no significant difference was recorded between the RMGI and CGI groups. The high sealing ability of 
the CRGI could be attributed to its strong natural adhesion to tooth structure. Also, it may be due to CRGI's greater compressive and tensile strength ${ }^{(12)}$. Ceramic reinforcement of GIC may be responsible for the higher strength of CRGI than that of other materials rendering the material highly resistant to fracture or cracks. Moreover, its high modulus of elasticity results in a strong chemical adhesion to the structure of the tooth that ensures low interfacial stress ${ }^{(11)}$. In the current study, CRGI's superior sealing ability agrees with Woodfine et al ${ }^{(10)}$ who demonstrated that CRGI provides an excellent natural adhesion to tooth structure.

Regarding RMGI, it showed less sealing ability as compared to CRGI with a notable difference and this is in agreement with Morabito and Defabianis ${ }^{(34)}$ who reported that although RMGICs show greater bond strength to dental hard tissues than traditional materials, microleakage tests showed changeable performance. Same findings were reported by El Negoly et al ${ }^{(28)}$ who revealed also a notable difference between CRGI and RMGIC restorative materials with CRGI showed better marginal seal with the tooth structures than RMGI.

In the present study, the CGI exhibited the greatest microleakage from all groups, however there was no notable difference between mean microleakage scores of RMGI and CGI groups. This may be due to the difference in the early strength of GICs, which is primarily influenced by the chemical composition of the glass powder and its microstructure, the origin, concentration and molecular weight of polyacrylic acid ${ }^{(35)}$. This affected their proper adherence to the tooth structure and so, marginal gaps occur. Furthermore, the incorporation of 5\% hydroxyethyl methacrylate "HEMA" in the RMGI renders the material to have superior physical properties than those of CGICs and overcome the problems of hardening difficulties. Hence, improving the bond strength to the tooth structure, although it was not sufficient to show a statistically significant difference. This goes in line with Castro and Fegial ${ }^{(36)}$, Gupta et al ${ }^{(37)}$ and Pontes et al ${ }^{(38)}$ who indicated that RMGI-filled cavities had less leakage than comparable CGI-filled cavities. However, they showed a significant difference between them. This significant effect could be referred to the use of different methodology or different types of GICs from those used in the present study. On the contrary, Puckette et al ${ }^{(39)}$ reported that the degree of microleakage of CGICs was notably less than those of RMGICs.

The high success rate of Amalgomer CR may be due to efficient cavity preparation, improved physical and adhesive properties. Moreover, its content of ceramic filler, which is an inert substance that do not take part in thermal expansion and contraction. However, some limitations were noted regarding handling techniques and technical difficulties of the material. Amalgomer $\mathrm{CR}$ is hand-mixed which might incorporate voids into the material and the effect of hand-mixing was not evaluated in the present study. Furthermore, appropriate amount of powder and liquid dispensed prior to mixing had to be of great concern. Another possible limitation was that, the in vitro studies are not capable to reproduce the same conditions of the human oral environment completely, although the attempt of the methodology to simulate the oral conditions. The well- controlled environment of the in vitro studies may exaggerate the bonding capabilities which is difficult to be achieved in the clinical situation. In our study, restorative materials were placed in class $\mathrm{V}$ cavities prepared using a carbide bur on extracted caries-free molars. However, clinically, class $\mathrm{V}$ restorations are placed due to carious lesions. Therefore, enamel/dentin substrate characteristics in these situations may be different from the bonding substrates encountered in this in vitro study.

Within the limitations of this study, CRGI had shown encouraging results. Therefore, it could be considered as an effective restorative material due to its better marginal seal with tooth structure than both RMGI and CGI. 


\section{CONCLUSION}

Ceramic reinforced glass ionomer revealed the highest sealing ability in class $\mathrm{V}$ primary molars when compared to RMGI and CGI. Further clinical studies are necessary to determine CRGI clinical performance.

\section{ACKNOWLEDGEMENT}

The author would like to acknowledge the staff members of the Dental Materials Department at the Faculty of Dentistry, Alexandria University for providing the necessary resources to make this study possible.

\section{REFERENCES}

1. Fragkou S, Balasouli C, Tsuzukibashi O, Argyropoulou A, Menexes G, Kotsanos N, Kalfas S. Streptococcus mutans, Streptococcus sobrinus and Candida albicans in oral samples from caries-free and caries-active children. Eur Arch Paediatr Dent. 2016; 17:367-75.

2. Moshaverinia A, Navas A, Jahedmanesh N, Shah KC, Moshaverinia A, Ansari S. Comparative evaluation of the physical properties of a reinforced glass ionomer dental restorative material. J Prosthet Dent. 2019; 122:154-9.

3. Sidhu SK, Nicholson JW. A review of glass-ionomer cements for clinical dentistry. J Funct Biomater. 2016; 7:16. doi: 10.3390/jfb7030016

4. Ansgar C, Shiu-Yin. A review of Glass Ionomer Restorations in the primary dentition. J Can Dent Assoc. 1999; 65:491-5.

5. Menezes-Silva R, Cabral RN, Pascotto RC, Borges AFS, Martins CC, Navarro MFL, Sidhu SK, Leal SC. Mechanical and optical properties of conventional restorative glassionomer cements - a systematic review. J Appl Oral Sci. 2019;27: e2018357.

6. Webman M, Mulki E, Roldan R, Arevalo O, Roberts JF, Garcia-Godoy F. A retrospective study of the 3-year survival rate of resin-modified glass-ionomer cement class II restorations in primary molars. J Clin Pediatr Dent. 2016; 40:8-13.

7. Piwowarczyk A, Ottl P, Lauer HC, Büchler A. Laboratory strength of glass ionomer cement, compomers, and resin composites.J Prosthodont. 2002:11:86-91.
8. Lagarde M, Francois P, Goff SL, Attal JP, Dursun E. Structural and long-term mechanical properties from a resinmodified glass ionomer cement after various delays of light-activation. Dent Mater J. 2018;37: 874-9.

9. Anusavice KJ, Phillips RW. Science of dental materials, 11th ed. St Louis: WB Saunders. 2003;482.

10. Woodfine B, Lancefield A. Modern glass ionomers-Meeting the amalgam ISO 1559 challenge. In Journal Of Dental Research 2003 Jun 1 (Vol. 82, Pp. B258-B258). 1619 Duke St, Alexandria, Va 22314-3406 Usa: Int Amer Assoc Dental Researchi Adr/Aadr.

11. Amalgomer Technology: Advanced Healthcare Ltd. Dental Products Manufacturer. Available at: http://www.ahl.uk.com/ index.php/products/amalgomer. Accessed on Dec 7, 2020.

12. Ayad NM, Elnogoly SA, Badie OM. An invitro study of the physico-mechanical properties of a new esthetic restorative versus dental amalgam. Rev Clin Pesq Odontol. $2008 ; 4: 137-44$

13. Deepa G, Shobha T. A clinical evaluation of two glass ionomer cements in primary molars using atraumatic restorative treatment technique in India: 1 year follow up. Int J Paediatr Dent. 2010;20: 410-8.

14. Ayna B, Celenk S, Atas O, Tümen EC, Uysal E, Toptanci IR. Microleakage of glass ionomer based restorative materials in primary teeth: An in-vitro study. Niger J Clin Pract. 2018;21:1034-7.

15. Walia R, Jasuja P, Verma KG, Juneja S, Mathur A, Ahuja L. A comparative evaluation of microleakage and compressive strength of Ketac Molar, Giomer, Zirconomer, and Ceram-x: An in vitro study. J Indian Soc Pedod Prev Dent. 2016; 34:280.

16. Salman KM, Naik SB, Kumar NK, Merwade S, Brigit B, Jalan R. Comparative evaluation of microleakage in Class $\mathrm{V}$ cavities restored with giomer, resin-modified glass ionomer, zirconomer and nano-ionomer: An In vitro study. Int Clin Dent Res Organ. 2019; 11:20.

17. Haller B, Hofmann N, Klaiber B, Bloching U. Effect of storage media on microleakage of five dentin bonding agents. Dent Mater. 1993; 91:191-7.

18. Waggoner WF, Nelson T. Restorative dentistry for the primary dentition. In: Nowak AJ, Christensen JR, Mabry TR, Townsend JA, Wells MH. Pediatric dentistry; Infancy through adolescence. $6^{\text {th }}$ edition, St.Louis, Missouri:El Sevier Saunders; 2019;304-28. 
19. Tao L, Pashley DH. Shear bond strengths to dentin: effects of surface treatments, depth and position. Dent Mater 1988; 4: 371-8.

20. Masih S, Koshy G, Joshi JL. Comparative evaluation of the microleakage of two modified glass ionomer cements on primary molars. An in vivo study. J Indian Soc Pedod Prev Dent. 2011; 29:135-9.

21. Muangmingsuk A, Senawongse P, Yudhasaraprasithi S. Influence of different softstart polymerization techniques on marginal adaptation of class V restorations. Am J Dent. $2003 ; 16: 117-9$.

22. Sidhu SK, Carrick TE, McCabe JF. Temperature mediated coefficient of dimensional change of dental tooth-coloured restorative materials. Dent Mater 2004; 20: 435-40.

23. Toledano M, Osorio E, Osorio R, Garcia-Godoy F. Microleakage of class $\mathrm{V}$ resin-modified glass ionomer and compomer restorations. J Prosthet Dent 1999; 81: 610-5.

24. Wadenya RO, Yego C, Mante FK. Marginal miroleakage of alternative restorative treatment and conventional glass ionomer restorations in extracted primary molars. J Dent Child. 2010; 77:32-5.

25. Silveira de Araújo C, Incerti da Silva T, Ogliari FA, Meireles SS, Piva E, Demarco FF. Microleakage of seven adhesive systems in enamel and dentin. J Contemp Dent Prac 2006; 7 : 26-33.

26. Piva E, Meinhardt L, Demarco FF, Powers JM. Dyes for caries detection: influence on composite and compomer microleakage. Clin Oral Investig. 2002; 6:244-8.

27. Wang Y, Darvell BW. Hertzian load-bearing capacity of a ceramic-reinforced glass ionomer cement stored wet and dry. Dent Mater. 2009; 25:279-86.

28. El-Negoly SA, Ibrahim FM, Ellatif AA. Immunohistochemical expression of tooth pulp dendritic cells as a response to ceramic reinforced glass ionomer restorative materials. Egypt Dent J. 2009; 55:93-102.
29. Watson TF, Sidhu SK, Griffiths BM. Ionomers and composites at the tooth interface. In: Proceedings of the $2^{\text {nd }}$ international symposium on glass ionomers. Glass ionomers: The next generation. Hund PR, editor. Chicago II: Quintessence Publishing. 1994;123.

30. Xie H, Zhang F, Wu Y, Chen C, Liu W. Dentin bond strength and microleakage of flowable composite, compomers and glass ionomer cement. Aust Dent J. 2008; 53:325-33.

31. Gupta SK, Gupta J, Saraswathi V, Ballal V, Acharya SR. Comparative evaluation of microleakage in class $\mathrm{V}$ cavities using various glass ionomer cements: An in-vitro study. J Interdiscip Dent. 2012; 2:164-9.

32. Krifka S, Federlin M, Hiller KA, Schmalz G. Microleakage of silorane- and methacrylate-based class V composite restorations. Clin Oral Investig. 2012; 16:1117-24.

33. Puckette AD, Fitchie JG, Karns L, Dellinger TM, Inman CC. Microleakage of compomer compared to conventional and hybrid ionomers. Quintessence Int. 2001; 32:49-54.

34. Morabito A, Defabianis P. The marginal seal of various restorative materials in primary molars. J Clin Pediatr Dent. 1997; 22:51-4.

35. Retief DH, Mandras RS, Russell CM, Denys FR. Evaluation of the syntac bonding system. Am J Dent. 1993; 6:17-21.

36. Castro A, Fegial RF. Microleakage of a new improved glass ionomer restorative material in primary and permanent teeth. Pediatr Dent. 2002; 24:23-8.

37. Gupta KV, Verma P, Trivedi A. Evaluation of microleakage of various restorative materials: An in vitro study. J Life Sci. 2011; 3:29-33.

38. Pontes DG, Guedes-Neto MV, Cabral MF, Cohen-Carneiro F. Microleakage evaluation of class $\mathrm{V}$ restorations with conventional and resin-modified glass ionomer cements. Oral Health Dent Manag. 2014; 13:642-6.

39. Puckette AD, Fitchie JG, Bennett B, Hembree JH. Microleakage and thermal propertied of hybrid ionomer restoratives. Quintessence Int. 1995;26:577-81. 